\title{
Exploring situational fears of children and adolescents
}

\author{
RAMYA RAJA AND K. AROCKIAMARAICHELVI
}

Received: 07.10.2016; Revised: 06.11.2016; Accepted: 18.11.2016

See end of the paper for authors' affiliations

\section{RAMYA RAJA}

Department of Human Development, Avinashilingam Institute for Home Science and Higher Education for Women University, COIMBATORE (T.N.) INDIA

Email : ramyaraja.in@gmail.com; mails4ramyaraja@gmail.com
ABSTRACT : Fear are the most common problem related to sensitivity in children. Many children experience the fear of a particular thing or a particular situation at some point in their development. The change in the fears of children and adolescents with increasing age is expressed bycognitive and social development. The situational fears may not be serious if it occurs occasionally. In a case where the child fails to secure parental support, the situation fear may develop to the point where the child is seriously hampered in social relationships, developing a fear of the unfamiliar that can remain for many years. Withthis background and the current reality of children being more fearful than the past, this study attempted to evaluate the reliability of situational fear producing factors among children of 4-14 years. The gender and age specific differences were also explored. The present study was conducted among 200 school going children of age 4-14 years, in Coimbatore district through $\mathrm{k}$ in 10 sampling technique with certain inclusion criteria. The investigator used five-point rating scale to secure adequate data on situational fears. ' $t$ ' test statistic was done to appraise the gender specific and age specific differences. The selected three age groups were found to have situational fears at varying degrees. However, the number of significant variations on gender and age was very few, which projects that these variables do not influence the situational fears of children between 4-14 years. An elaborate study has to be undertaken to find out what causes certain other fears to increase in its intensity with increase in age as well the variation in gender.

KEY WORDS: Fears of children, Adolescents, Situational fear, Gender, Age specific differences

- HOW TO CITE THIS PAPER : Raja, Ramya and Maraichelvi, K. Arockia (2016). Exploring situational fears of children and adolescents. Asian J. Home Sci., 11 (2) : 425-428, DOI: 10.15740/HAS/AJHS/11.2/ 425-428. 